\title{
The Endoscopic Endonasal Management of Anterior Skull Base Meningiomas
}

\author{
Matteo Zoli ${ }^{1,2}$ Federica Guaraldi ${ }^{1,2}$ Ernesto Pasquini ${ }^{3}$ Giorgio Frank ${ }^{1}$ Diego Mazzatenta ${ }^{1,2}$ \\ ${ }^{1}$ Center of Pituitary and Endoscopic Skull Base Surgery, IRCCS Istituto \\ delle Scienze Neurologiche di Bologna, Bologna, Italy \\ 2 Department of Biomedical and Neuromotor Sciences, University of \\ Bologna, Bologna, Italy \\ Address for correspondence Matteo Zoli, MD, Center of Diagnosis \\ and Cure of Pituitary and Skull Base Tumors, IRCCS Institute of \\ Neurological Sciences of Bologna, DIBINEM, University of Bologna, Via \\ Altura 3, Bologna 40124, Italy (e-mail: matteo.zoli4@unibo.it).
}

${ }^{3}$ Department of ENT, Ospedale Bellaria, Bologna, Italy

J Neurol Surg B 2018;79(suppl S4):S300-S310.

\begin{abstract}
Introduction The endoscopic endonasal approach (EEA) might seem an "unnatural" route for intradural lesions such as meningiomas. The aim of this study is to critically revise our management of anterior skull base meningiomas to consider, in what cases it may be advantageous.

Material and Methods Each consecutive case of anterior skull base meningioma operated on through an EEA or combined endoscopic-transcranial approach at our institution, between 2003 and 2017, have been included. Tumors were classified on the basis of their location and intra or extracranial extension. Follow-up consisted of an MRI (magnetic resonance imaging) and a clinical examination 3 months after the surgery and then repeated annually.

Results Fifty-seven patients were included. The most common location was the tuberculum sellae (62\%), followed by olfactory groove (14\%), planum sphenoidale $(12 \%)$, and frontal sinus (12\%). Among these, $65 \%$ were intracranial, $7 \%$ were extracranial, and $28 \%$ both intra and extracranial. Radical removal was achieved in 44 cases (77\%). Complications consisted in $10 \mathrm{CSF}$ (cerebrospinal fluid) leaks (17.6\%), 1 overpacking (1.7\%), and 1

\section{Keywords}

- endoscopic endonasal surgery

- meningiomas

- anterior skull base

- tuberculum sellae

- olfactory groove

- frontal sinus

- transcranial approaches asymptomatic brain ischemia (1.7\%). Visual acuity and campimetric deficits improved respectively in 67 and $76 \%$ of patients. Recurrence rate was of $14 \%$.

Conclusions EEA presents many advantages in selected cases of anterior skull base meningioma. However, it is hampered by the relevant risk of CSF leak. We consider that it could be advantageous for planum/tuberculum sellae tumors. Conversely, for olfactory groove or frontal sinus meningiomas, it can be indicated for tumors with extracranial extension, while its role is still debatable for purely intracranial forms as considering our surgical results, it could be advantageous for midline planum/tuberculum sellae tumors. Conversely, it can be of first choice for olfactory groove or frontal sinus meningiomas with extracranial extension, while its role for purely intracranial forms is still debatable.
\end{abstract}

\section{Introduction}

The role of endoscopic endonasal approach (EEA) in anterior skull base meningioma surgery has been widely debated in current literature. ${ }^{1-9}$ Most of these tumors are located intradurally; therefore, their removal through a ventral route requires

received

March 8, 2018

accepted after revision

July 22, 2018

published online

August 27, 2018

an osteodural opening with the risk of postoperative cerebrospinal fluid (CSF) leak. ${ }^{1-9}$ This could suggest that such approach might seem "unnatural" because it does not follow natural surgical corridors and increases the risk of complications; however, many papers have considered that it could give many advantages both for surgeons and for patients. ${ }^{1-15}$ Indeed,

(c) 2018 Georg Thieme Verlag KG Stuttgart · New York
DOI https://doi.org/ 10.1055/s-0038-1669463. ISSN 2193-6331. 
it adopts a completely extracranial route, which avoids any brain retraction, nerves or arteries crossing and manipulation, it allows an early devascularization, and it gives the possibility to remove the tumor, adopting the arachnoid as cleavage plane, and therefore, reducing the risk of damage by perforating vessels and optochiasmatic feeders. ${ }^{1-15}$

In literature, many authors have reported their surgical experiences with anterior skull base meningiomas operated on through the EEA, demonstrating its feasibility and safety in selected cases. ${ }^{7,8,14-18}$ Few meta-analyses or review articles have compared this approach to the transcranial ones. ${ }^{1,5,6}$ However, their conclusions are often impaired by multiple biases, due to the more limited extension of the endoscopic series, the shorter follow-up and the different case selection. ${ }^{1,5,6}$ Moreover, anterior skull base meningiomas are a heterogenous group, including different locations, histotypes and symptoms.

In this paper, we analyze our surgical experience with anterior skull base meningiomas operated on through the EEA, with the aim to critically revise our surgical indications to consider for which cases it could be advantageous, improving the clinical and surgical outcome.

\section{Materials and Methods}

Each consecutive case of anterior skull base meningioma operated on at our institution (Center of Pituitary and Endoscopic Skull Base Surgery, IRCCS Institute of Neurological
Sciences of Bologna, Bologna, Italy) through an EEA (pure or combined with transcranial approach) from July 2003 to December 2017 has been retrospectively included in the series. All patients underwent preoperative MRI (magnetic resonance imaging). This examination was reviewed to assess the location of the tumor on the basis of the implant of the meningioma. Four options were considered: frontal sinus, olfactory groove, planum, and tuberculum sellae. Moreover, the possible extracranial extension of the tumor in the paranasal sinuses was considered on a preoperative CT (computed tomography)scan and MRI ( - Figs. 1-3). Medical history of the patient was considered, focusing on previous surgeries or other treatment for these meningiomas.

Each case had a physical examination performed before surgery, and an ophthalmologic examination with visual field assessment, in case of compression of the optic nerves or chiasm, or whether the patient had reported visual disturbances. Our surgical technique has been already reported. ${ }^{16}$ Briefly, different corridors were chosen, depending on the location of the tumor (i.e., transcribriform for olfactory groove meningioma, transplanum/transtuberculum for tuberculum sellae meningioma). Closure technique consisted in a multilayer technique with fascia lata or a heterologous substitute (Biodesign, Cook Medical LLC, Blomington, IN. U.S.A.) placed intracranially/intradurally, followed by a second layer of same material placed intracranially/extradurally, finally covered by free graft or pedicled flap of mucoperiostium. Nasal cavities are then packed with gelfoam and Merocel (Merocel Corporation,

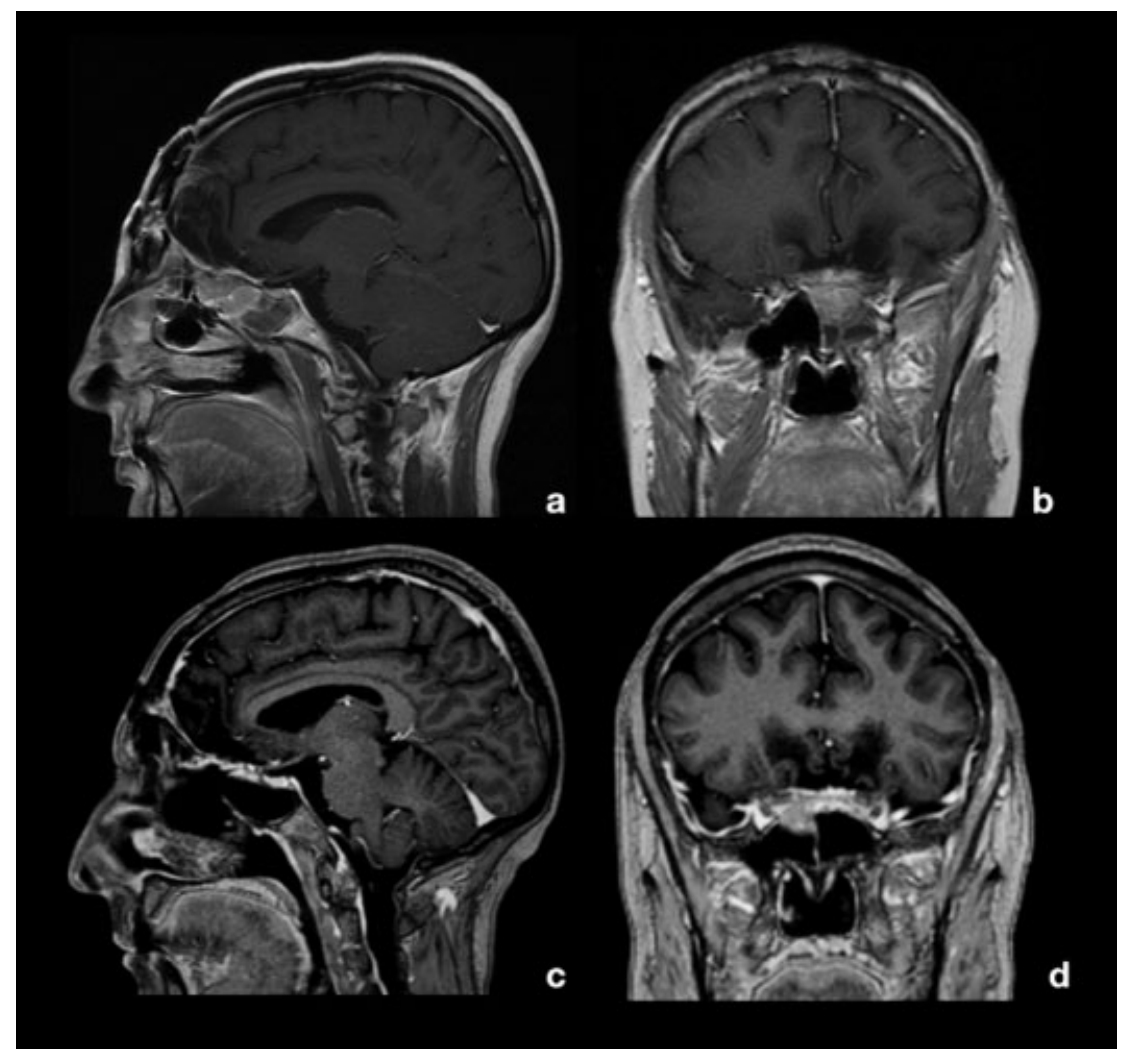

Fig. 1 MRI T1 after gadolinium coronal and sagittal slices. (a and b) Preoperative magnetic resonance imaging (MRI), showing an extracranial recurrent olfactory groove meningioma. The patient has been already operated on through a transcranial approach for an olfactory groove meningioma, which presented with extracranial recurrence in the ethmoid and sphenoid paranasal sinuses along with a sense of nasal obstruction. (c and d) Postoperative MRI. The tumor has been radically removed through a pure EEA (endoscopic endonasal approach). 


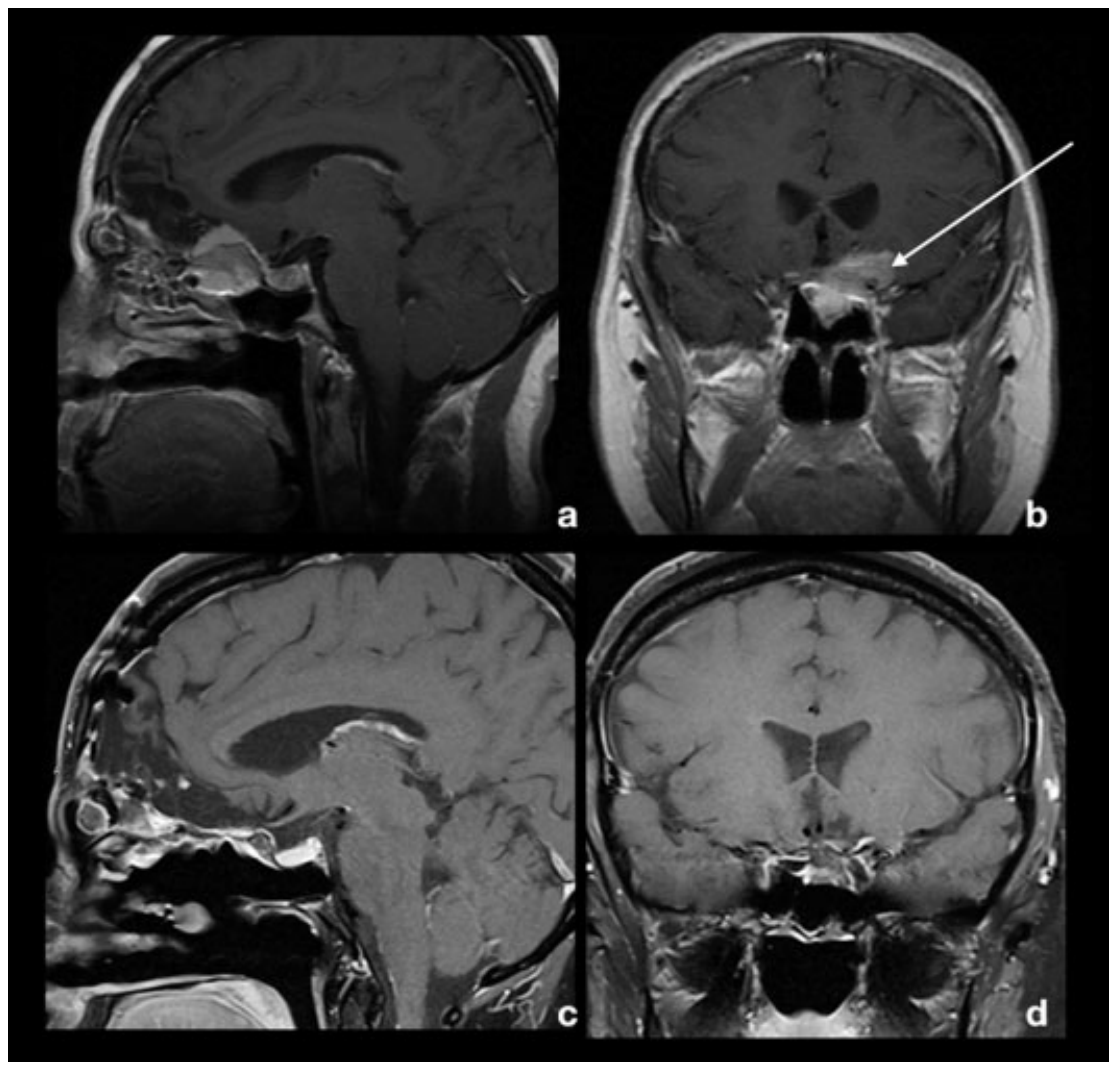

Fig. 2 MRI T1 after gadolinium coronal and sagittal slices. (a and b) Preoperative MRI (magnetic resonance imaging), showing a recurrent intra/ extracranial olfactory groove meningioma. The patient was operated on through a transcranial approach few years ago and presented at followup with this recurrence, invading the ethmoid. The intracranial portion of the tumor showed a lateral extension, beyond the limit of the internal carotid artery (ICA), which also was encased (white arrow). (c and d) Postoperative MRI. Considering the intramural extension of the tumor, a combined transcranial and endoscopic approach was preferred. The latter allowed the radical resection of the extracranial portion of the tumor, while the former was adopted to remove its intracranial component.

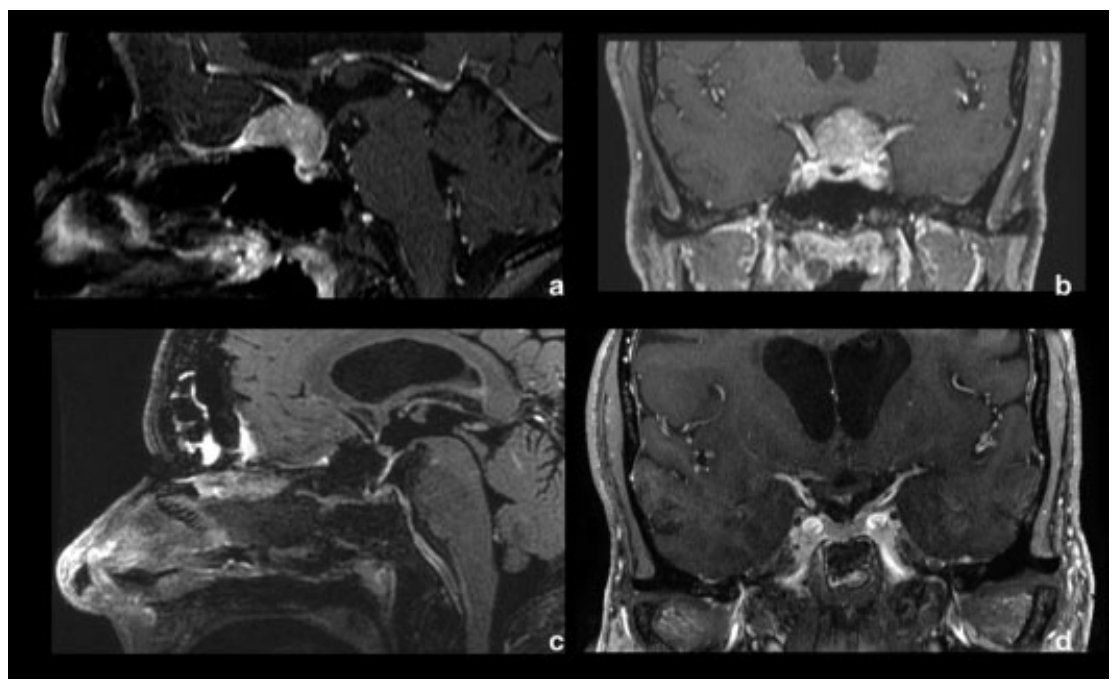

Fig. 3 MRI T1 after gadolinium coronal and sagittal slices. (a and b) Preoperative MRI, showing a tuberculum sellae meningioma, causing visual disturbances. (c and d) Postoperative MRI (magnetic resonance imaging). A radical resection of the tumor was achieved.

Mystic, CT. U.S.A.), which is kept for 75 hours after surgery. External lumbar drainage was not routinely adopted for risk of massive pneumocephalus after extended approaches. The adopted surgical approach for each case and its morbidity were considered, based on the medical records.
Follow-up consisted of a postoperative MRI before discharge that was repeated after 3 months and then annually. The tumor removal was assessed as radical if no remnants were visible on the 3-month MRI subtotal, if remnants were inferior than $20 \%$ of the initial mass, or partial if larger than 
Table 1 Location and extension of the meningiomas of the series

\begin{tabular}{|l|l|l|l|}
\hline Location & Intracranial & $\begin{array}{l}\text { Intra/ } \\
\text { extracranial }\end{array}$ & Extracranial \\
\hline $\begin{array}{l}\text { Tuberculum } \\
\text { sellae }\end{array}$ & 33 & 2 & 0 \\
\hline $\begin{array}{l}\text { Planum } \\
\text { sphenoidale }\end{array}$ & 3 & 4 & 0 \\
\hline $\begin{array}{l}\text { Olfactory } \\
\text { groove }\end{array}$ & 1 & 5 & 2 \\
\hline Frontal sinus & 0 & 5 & 2 \\
\hline
\end{tabular}

$20 \%$.Olfactory function was analyzed by specific questions to each patient at follow-up. The clinical outcome was considered, repeating the neurological and the ophthalmologic examinations after 3 months and then annually. Recurrence rate and complementary treatment were considered.

\section{Results}

Fifty-seven patients were included in the series. Mean age was of 58 years (standard deviation [SD]: 12.5), males were 15 (26\%) and females 42 (74\%). Thirteen cases (23\%) have been previously undergone a transcranial approach and 2 had also performed postoperative radiotherapy (3.5\%). The most common location was the tuberculum sellae (35 cases, 62\%), followed by olfactory groove ( 8 cases, $14 \%$ ), planum sphenoidale ( 7 cases, $12 \%$ ), and frontal sinus ( 7 cases, $12 \%$ ). As shown in -Table 1, 37 tumors (65\%) were completely intracranial, 4 (7\%) were completely extracranial with extension in the paranasal sinus and 16 were intra and extracranial (28\%).

Preoperative symptoms depended on the location of the tumor, as reported in - Table $\mathbf{2}$. Indeed, most of the patients with tuberculum sellae meningioma were presented with visual acuity or campimetric disturbances, (69 and 63\%, respectively,). Conversely, in case of olfactory groove or frontal sinus tumors anosmia, epistaxis, or nasal obstruction were the most common symptoms. In $91 \%$ of cases (52 patients) a purely EEA was chosen, tailoring the approach on the tumor location, such as transtuberculum for tuberculum sellae meningiomas or transcribriform for olfactory groove forms. Five patients (9\%) underwent a combined transcranial and EEA in the same surgery for meningiomas located in the frontal sinus in 2 cases, in the olfactory groove in other 2 and in the planum in 1 . All these cases were tumors with both extracranial expansion in the paranasal sinuses and with intracranial extension beyond the lateral limits of the approach, such as above the roof of the orbit or with encasement of the carotid artery and its major branches. The vast majority of cases were WHO grade I meningiomas (52 cases, 91\%), while 5 (9\%) presented with WHO grade II histological features, as reported in - Table 3.

Complications consisted in 10 postoperative CSF leaks (17.6\%), 1 overpacking (1.7\%) with transient visual worsening, and 1 brain ischemia (1.7\%), which had no neurological consequences to the patient ( - Table 4 ). In case of postoperative CSF leak, our management consisted in a prompt revision of the osteodural defective plastic. One developed meningitis required antibiotic therapy. No permanent sequelae due to these complications were observed in the series. The case of overpacking was immediately reoperated on and visual deficit was restored completely in the first 2 days.

Radical tumor removal, in patients operated on through a pure endoscopic endonasal approach, was achieved in 30 cases (86\%) of tuberculum sellae meningiomas, 4 (66\%) of planum, $4(80 \%)$ of olfactory groove, and $1(17 \%)$ of frontal sinus forms, while resection was radical in 4 of the 5 cases

Table 2 Preoperative symptoms

\begin{tabular}{|l|l|l|l|l|l|}
\hline Symptoms & & $\begin{array}{l}\text { Tuberculum } \\
\text { sellae }\end{array}$ & $\begin{array}{l}\text { Planum } \\
\text { sphenoidale }\end{array}$ & $\begin{array}{l}\text { Olfactory } \\
\text { groove }\end{array}$ & $\begin{array}{l}\text { Frontal } \\
\text { sinus }\end{array}$ \\
\hline Visual acuity deficit & None & 11 & 3 & 8 & 5 \\
\hline & Monolateral deficit (more than 6/10) & 9 & 3 & 0 & $1^{\text {a }}$ \\
\hline & Bilateral deficit (more than 6/10) & 9 & 0 & 0 & 0 \\
\hline & Monolateral deficit (less than 5/10) & 6 & 0 & 0 & $1^{\text {a }}$ \\
\hline & bilateral deficit (less than 5/10) & 0 & 1 & 0 & 0 \\
\hline Campimetric deficit & None & 13 & 5 & 8 & 7 \\
\hline & Incomplete BTH & 11 & 1 & 0 & 0 \\
\hline & Complete BTH & 10 & 0 & 0 & 0 \\
\hline & Monolateral blindness & 1 & 1 & 0 & 0 \\
\hline & Bilateral blindness & 0 & 0 & 0 \\
\hline & None & 35 & 7 & 1 & 0 \\
\hline & Anosmia & 0 & 0 & 8 \\
\hline & Nasal obstruction & 0 & 0 & 2 \\
\hline & Recurrent epistaxis & & 0 \\
\hline
\end{tabular}

${ }^{\mathrm{a}}$ sequelae due to previous surgeries 
Table 3 Histological features of the series

\begin{tabular}{|l|l|l|l|l|}
\hline Histology & Tuberculum sellae & Planum sphenoidale & Olfactory groove & Frontal sinus \\
\hline Meningothelial & 30 & 4 & 8 & 5 \\
\hline Transitional & 1 & 1 & 0 & 0 \\
\hline Psammomatous & 3 & 0 & 0 & 0 \\
\hline Chordoid & 0 & 1 & 0 & 0 \\
\hline Atypical & 1 & 1 & 0 & 2 \\
\hline
\end{tabular}

Table 4 Complications of the series

\begin{tabular}{|l|l|l|l|l|}
\hline Complications & Tuberculum sellae & Planum sphenoidale & Olfactory groove & Frontal sinus \\
\hline CSF leak & 7 & 1 & 1 & 1 \\
\hline Overpacking & 1 & 0 & 0 & 0 \\
\hline Brain ischemia & 1 & 0 & 0 & 0 \\
\hline
\end{tabular}

undergone a combined transcranial EEA approach (-Table 5). Preoperative visual acuity and campimetric deficits were completely normalized, respectively, in 11 (39\%) and 9 cases (38\%), and improved in 8 (28\%) and 9 patients (38\%). In 3 cases (5\%) a postoperative visual worsening was observed: 1 was a calcified tuberculum sellae meningioma with a dramatic visual reduction immediately after surgery. Other symptoms reported by the patients such as nasal obstruction and recurrent epistaxis were controlled in all cases. One new case of anosmia (1.7\%) was observed in 1 tubeculum sellae meningioma.

Recurrence rate was of $14 \%$. Among tuberculum sellae meningiomas only 1 recurrence (3\%) was observed 2 years after surgery and the patient underwent a transcranial surgery for the lateral extension of the tumor. One atypical planum meningioma recurred 3 months after the surgery, requiring radiotherapy, which allowed the control of the disease for 27 months then the patient died, because of tumor progression. Two further recurrences were observed in olfactory groove meningiomas, both were treated through radiotherapy. Finally, 4 cases of frontal sinus meningiomas showed recurrence, requiring endoscopic endonasal reintervention in 2 cases, and a combined treatment of surgery and radiotherapy in the other 2 . These latter both died due to tumor progression, respectively, 3 and 4 years after the first surgery. At follow-up (mean: 58 months, range: 3:183), 50 patients were alive $(88 \%)$ and $7(12 \%)$ dead (3 due to tumor progression and 4 due to causes not related to the disease).

Table 5 Clinical and surgical outcome of the series

\begin{tabular}{|c|c|c|c|c|c|}
\hline & & $\begin{array}{l}\text { Tuberculum } \\
\text { sellae }\end{array}$ & Planum sphenoidale & Olfactory groove & Frontal sinus \\
\hline \multirow[t]{3}{*}{$\begin{array}{l}\text { Tumor } \\
\text { removal }\end{array}$} & Radical & 30 & $\begin{array}{l}5 \text { ( } 1 \text { after a } \\
\text { combined a.) }\end{array}$ & $\begin{array}{l}5 \text { ( } 1 \text { after a } \\
\text { combined a.) }\end{array}$ & $\begin{array}{l}3 \text { ( } 2 \text { after a } \\
\text { combined a.) }\end{array}$ \\
\hline & Subtotal & 5 & 1 & 1 & 0 \\
\hline & Partial & 0 & 1 & $\begin{array}{l}1 \text { ( } 1 \text { after a } \\
\text { combined a) }\end{array}$ & 5 \\
\hline \multirow{4}{*}{$\begin{array}{l}\text { Visual acuity } \\
\text { deficit }\end{array}$} & Unchanged & 17 & 3 & 8 & 6 \\
\hline & Normalized & 10 & 1 & 0 & 0 \\
\hline & Improved & 6 & 2 & 0 & 0 \\
\hline & Worsening & 2 & 1 & 0 & 0 \\
\hline \multirow{4}{*}{$\begin{array}{l}\text { Campimetric } \\
\text { deficit }\end{array}$} & Unchanged & 17 & 4 & 8 & 7 \\
\hline & Normalized & 9 & 0 & 0 & 0 \\
\hline & Improved & 7 & 2 & 0 & 0 \\
\hline & Worsening & 2 & 1 & 0 & 0 \\
\hline Recurrence & & 1 & 1 & 2 & 4 \\
\hline
\end{tabular}

Abbreviations: combined a., combined endoscopic endonasal-transcranial approach. 
Table 6 Parameters adopted in the approach choice in our center

\begin{tabular}{|l|l|l|l|l|}
\hline & Frontal sinus & Olfactory groove & Planum & Tuberculum sellae \\
\hline Intracranial & Transcranial a. & Transcranial a. & EEA $^{\text {a }}$ & EEA $^{\text {a }}$ \\
\hline Intra/extracranial & EEA/combined a. & EEA/combined a. & EEA $^{\text {a }}$ & EEA $^{\text {a }}$ \\
\hline Extracranial & EEA & EEA & - & - \\
\hline
\end{tabular}

Abbreviations: combined a., combined endoscopic endonasal-transcranial approach; EEA, endoscopic endonasal approach; Transcranial a., transcranial approach.

a according to the selection criteria.

\section{Discussion}

Anterior skull base meningiomas represent a wide cohort of tumors with different location, extension and histotypes, which can be suitable for an EEA in selected cases. ${ }^{1-15}$ Indeed, as stated by Khan et al, careful case selection and surgical experience are the most relevant prognostic factors in endonasal endoscopic skull base meningioma surgery. ${ }^{18-21}$ Particularly, this approach should be reserved to strictly midline tumors, with no encasement of major vessels. ${ }^{22}$ Some Authors have proposed the presence of brain edema and the lack of cortical cuff as 2 other relevant parameters in patients' selection for this surgery. ${ }^{15}$ On the basis of our experience, we agree with Koutourousiou et al, who observed that these factors could impair the achievement of gross tumor removal through a ventral approach. ${ }^{15}$ In our series, 1 case was a complete calcified meningioma, which developed a dramatic worsening of visual function after surgery. According to current literature, we consider that this additional element constitutes a relevant limitation to EEA. ${ }^{1-15}$

Critically reviewing our indications, we observed that our case selection for EEA was based on 2 main parameters. The first one was represented by tumor location and the second by its intra or extracranial extension (-Table 6). Indeed, we consider that for frontal sinus and olfactory groove meningiomas the ventral approach was our first choice, in case of completely extracranial location. On the other hand, a tran- scranial approach was preferred for complete intracranial forms, while for midline intraand extracranial tumors we chose a purely endoscopic approach and a combined endoscopic transcranial, in case of paramedian extension or major vessels encasement. Conversely, for all midline planum/tuberculum meningiomas, a purely endoscopic approach has progressively become the approach of choice in our center over the last decade (-Fig. 4 ).

Frontal sinus or olfactory groove meningiomas with a complete extracranial extension grow into the paranasal sinuses and thus, the EEA allowed us to approach them directly through a short and straight trajectory, avoiding brain retraction as well as the major invasiveness given by transfacial approaches 1-15,23,24 (-Fig. 5). Similarly, this approach permits us to manage effectively intra and extracranial forms, when they are purely midline; while we preferred a combined endoscopic transcranial approach, in case of lateral extension. When these tumors present an intracranial extension, the most technically demanding maneuver is represented by the dissection of the tumor at its brain interface to avoid any direct damage or bleedings ${ }^{15,19}$ (-Fig. 6). The tumor removal follows the same rules valid for microsurgery, such as early devascularization, progressive central debulking and bimanual technique. For these invasive meningiomas, eroding the skull base and extending into the paranasal sinuses, the risk of postoperative CSF leak is present not only for EEA but also for alternative transcranial and transfacial approaches, which require as well a plastic

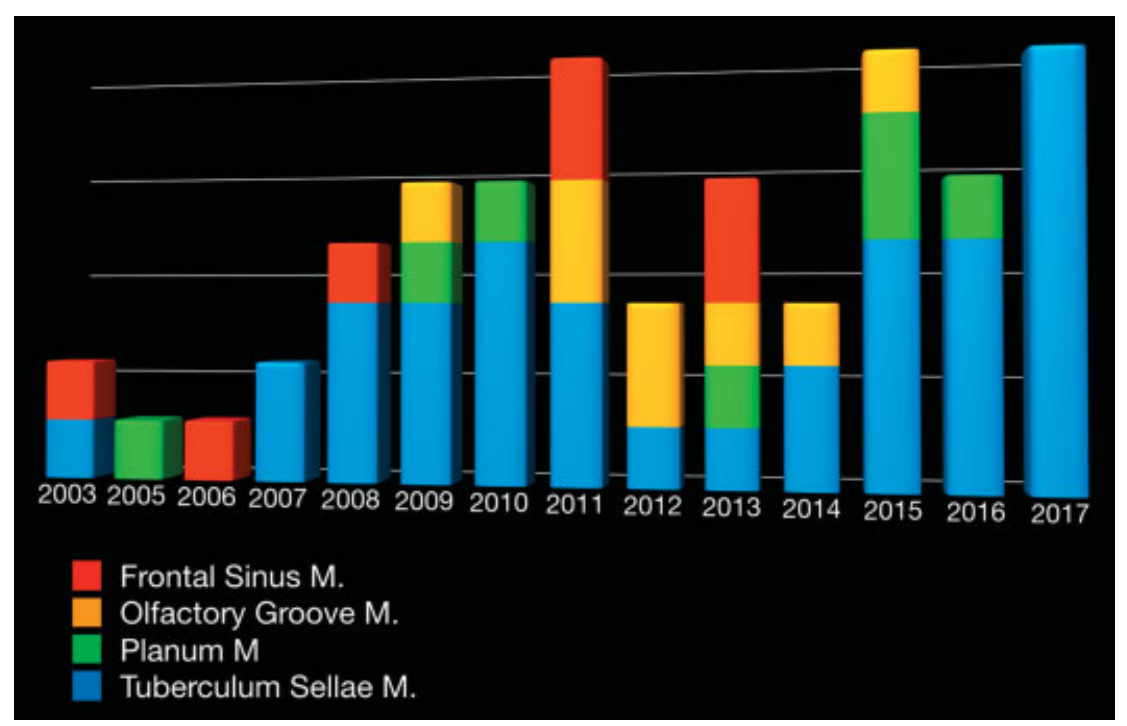

Fig. 4 Illustrative graph to show the learning curve of our center in the considered period (M: meningiomas). 


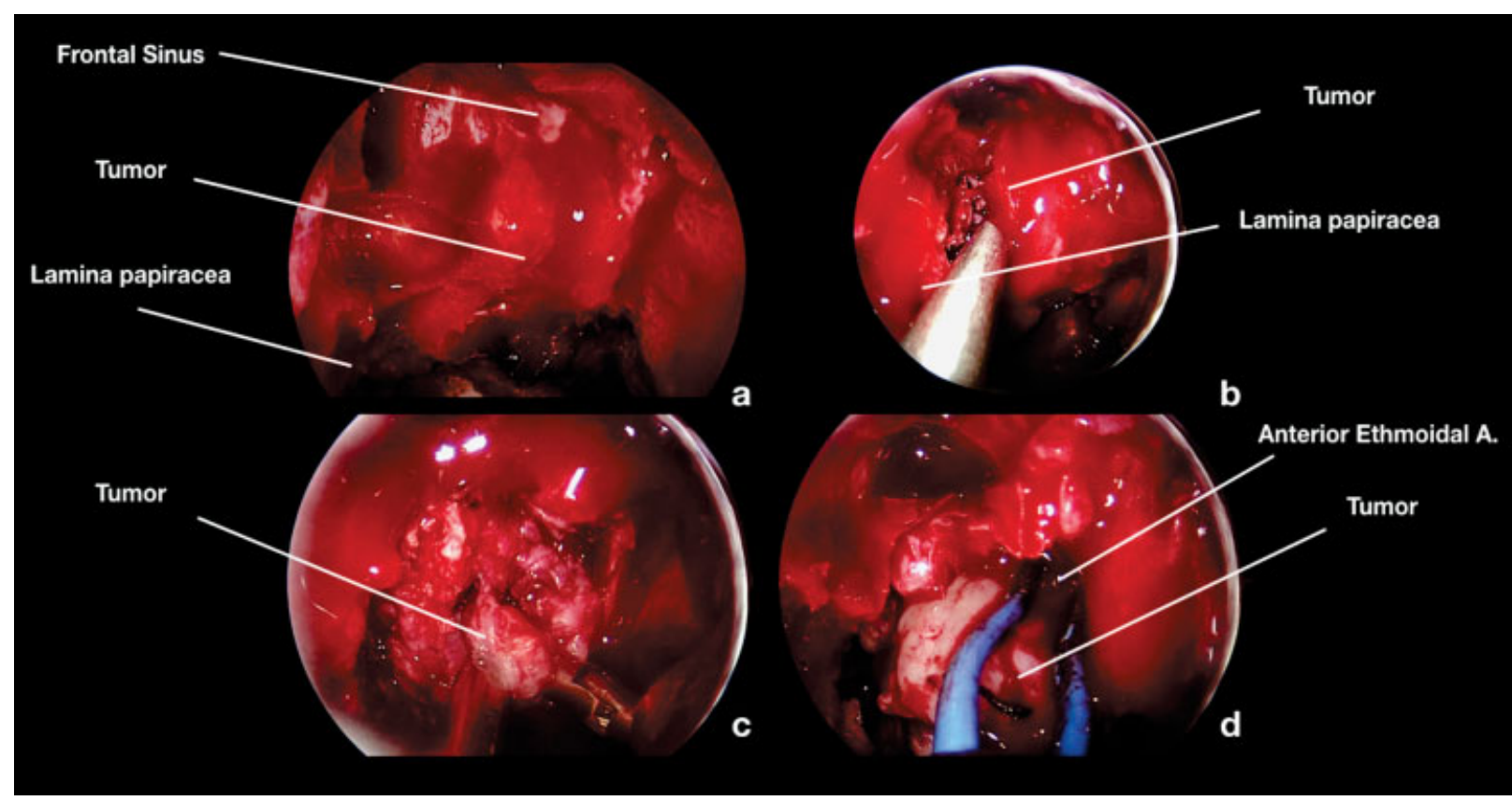

Fig. 5 Intraoperative images. $30^{\circ}$ scope. Endoscopic endonasal removal of an extracranial olfactory groove meningioma. (a) After a complete bilateral ethmoidectomy, the tumor is visible as an abutting mass in the ethmoid. (b and c) The tumor is dissected from the surrounding bone structures and then resected also using a debrider. (d) The coagulation of the ethmoid arteries allows the devascularization of the tumor.

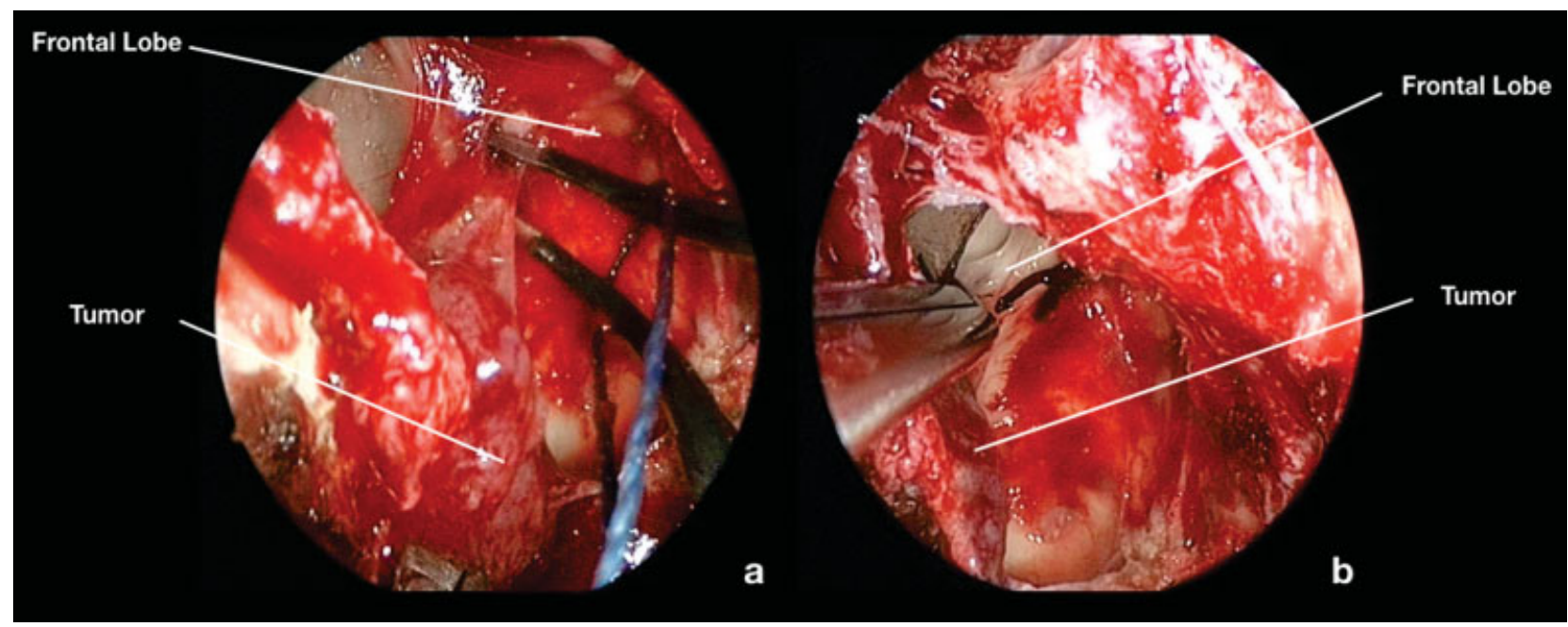

Fig. 6 Intraoperative images. $30^{\circ}$ scope. Endoscopic endonasal removal of an intracranial olfactory groove meningioma. A and B. After central debunking of the tumor, it can be cleaved from the brain. As in microsurgery, it is possible to coagulate and cut the feeders of meningioma, to avoid bleeding during surgery.

reconstruction of skull base ( $\mathbf{- F i g . ~} \mathbf{7}$ ). Thus, the ventral route can be considered advantageous in such selected cases.

In our series, the majority of intracranial meningiomas were tuberculum sellae (33 cases), followed by planum (3 cases) and 1 olfactory groove meningioma. The latter was a completely anosmic patient, who refused a transcranial approach with a tumor not suitable for alternative treatment such as radiosurgery. Although, our considerations are based on this single case, we believe that EEA should be preferred in very selected cases of olfactory groove meningiomas, mainly represented by small size lesions or tumors with extracranial extension in the ethmoid sinuses in anosmic patients. ${ }^{25}$ Indeed, the risk of CSF leak has been assessed at 30\% by
Koutourousiou et al for these tumors, while Ruggeri et al have found a rate of $7.97 \%$ after a transcranial approach in their meta-analysis. ${ }^{6,15}$ Moreover, differently from an EEA, through an open approach it could be possible to spare the olfactory fibers, eventually preserving the olfactory function. Furthermore, the transcranial approaches have developed in the last years, moving toward a minimally invasive, retractorless technique requiring a really small cranial opening. ${ }^{6}$ This is leading to an overall reduced morbidity of open approaches, particularly regarding the risk of seizures or brain damage, which have been rarely reported in the most modern series. ${ }^{6}$

In our experience, the most common indication for intracranial meningiomas was represented by planum and tuberculum 


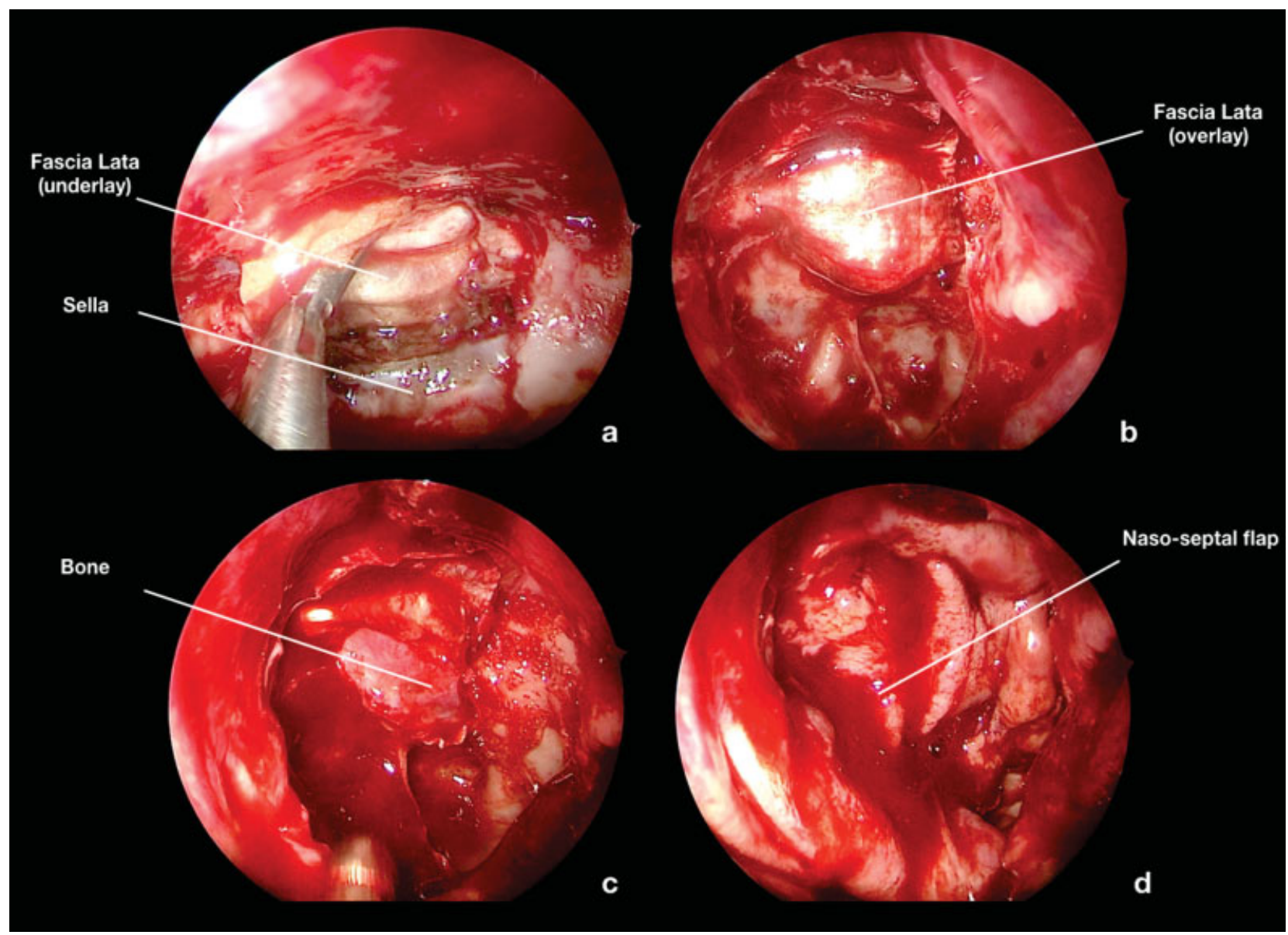

Fig. 7 Intraoperative images. $0^{\circ}$ scope. Multilayer plastic repair. (a) The former layer is represented by fascia lata, placed intracranially intradurally. (b) The following is constituted by a further layer of fascia lata, placed intracranially and extradurally. (c) A piece of bone is placed intracranially to reconstruct the osteodural defect. (d) A nasoseptal flap is placed to cover the previous layers.

sellae meningiomas. In these patients, the osteodural opening at the level of planum/tuberculum and thus the risk of a postoperative CSF leak might be counterbalanced to the possible advantages, particularly for restoring the visual function. ${ }^{1-15,24,26,27}$ In our series, visual acuity and campimetric deficits were improved or restored in 67 and $76 \%$ of cases, respectively. In a recent review of the literature, the improvement of visual deficit after an EEA has been assessed as approximately $80.09 \%{ }^{6}$. Such rate proved greater than after a transcranial approach (62.24\%). ${ }^{6}$ This result can be explained considering that the ventral route allows us to remove the tumor, avoiding any manipulation of the optic chasm and nerves in particular at the early stages of surgery, when they are stretched by the meningioma ( $\mathbf{- F i g}$. 8). Therefore, the early decompression of the optic apparatus may avoid any direct injury and thus, could yield a better functional outcome. Moreover, the EEA can also reduce the risk of indirect injury to the optic structures, sparing its blood supply (- Fig. 9). Indeed, differently from transcranial approach, requiring to open the arachnoid layer and working between the different corridors given by optic nerve and ICA, EEA permits to cleave the tumor by the surrounding arachnoid, avoiding any damage to their arterial supply, arising from the carotid artery, namely, the superior hypophyseal artery. ${ }^{1-15}$ Moreover, EEA allows us to resect safely, also portions of the tumor medially invading the optic canal. ${ }^{28-30}$ These more favorable visual results have been criticized for the possible bias due to the different size of meningiomas treated through the endoscopic and transcranial approach. ${ }^{1,5,6}$ We agree that at the beginning of the learning curve, larger meningiomas were not considered suitable for the ventral resection. However, in the series reported in literature, also meningiomas of relevant size were treated with a pure EEA with good visual outcome also for these cases. ${ }^{1-15}$ In our experience, few cases of postoperative permanent anosmia have been observed. At early follow-up, this symptom is commonly reported by the patient; however, we have observed a recovery in the vast majority of cases within 6 to 12 months after surgery. We believe that this result can be due to the limited extension of our endoscopic endonasal approach. Indeed, we are used to perform a mono-lateral posterior ethmoidectomy, sparing the contralateral olfactory fibers and for selected cases of meningiomas posterior to the sphenoethmoidal junction, the approach was limited to an anterior sphenoidotomy avoiding any ethmoidectomies.

A limit of this study is represented by the inhomogeneous amount of the different types of meningiomas, which is due to a selection bias. Moreover, these cases have been included over a long period of time ( 15 years) and the results can be 


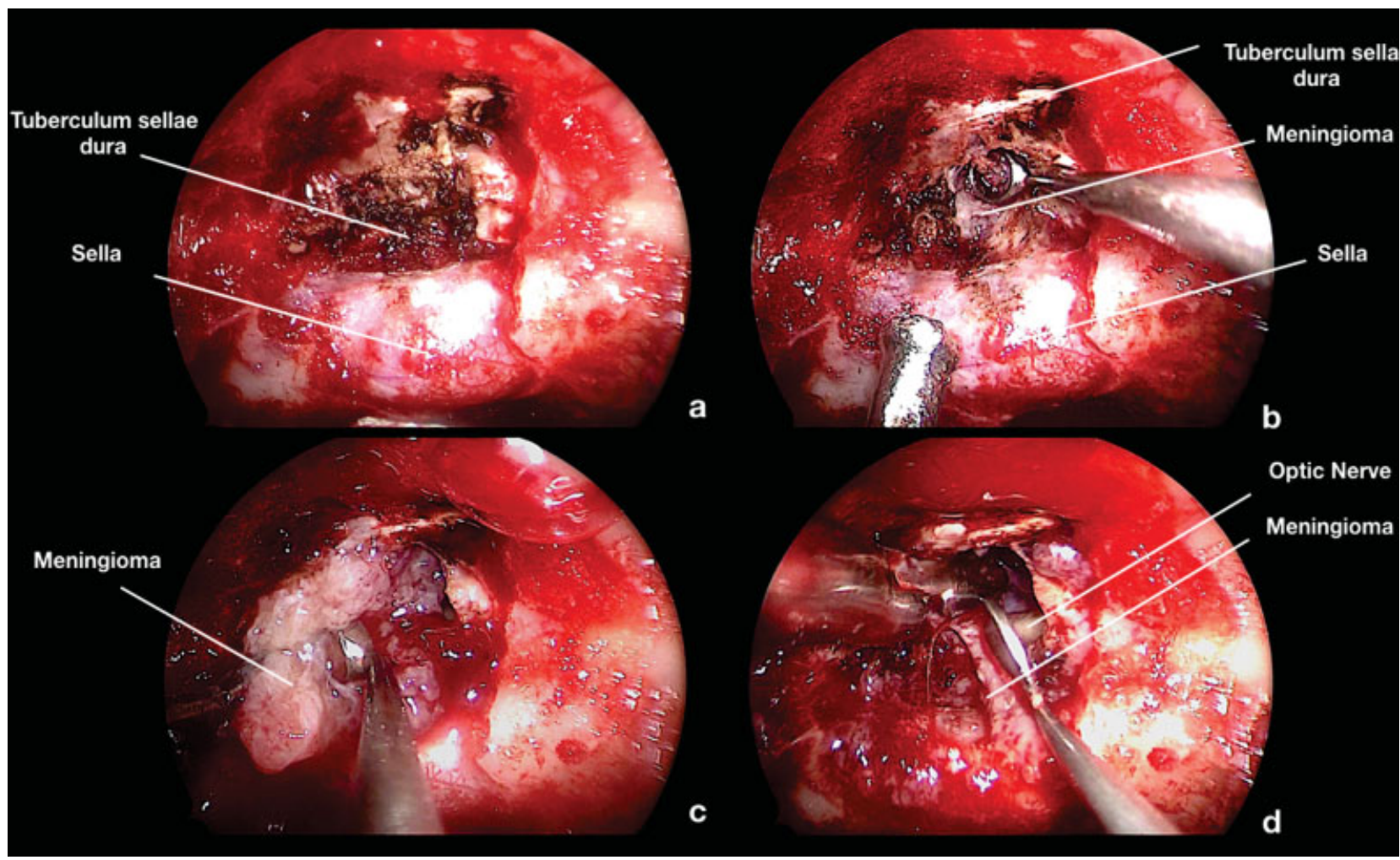

Fig. 8 Intraoperative images. $0^{\circ}$ scope. Endoscopic endonasal removal of a tuberculum sellae meningioma. (a) The dural base of the meningioma, corresponding to the tuberculum, was widely coagulated at the beginning of the surgery to vascularize the tumor. (b) The meningioma is centrally debulked to reduce its mass, with the same microsurgical technique. (c and $\mathbf{d}$ ) The tumor can be cleaved from the surrounding structures, avoiding any manipulation of the optic nerves.

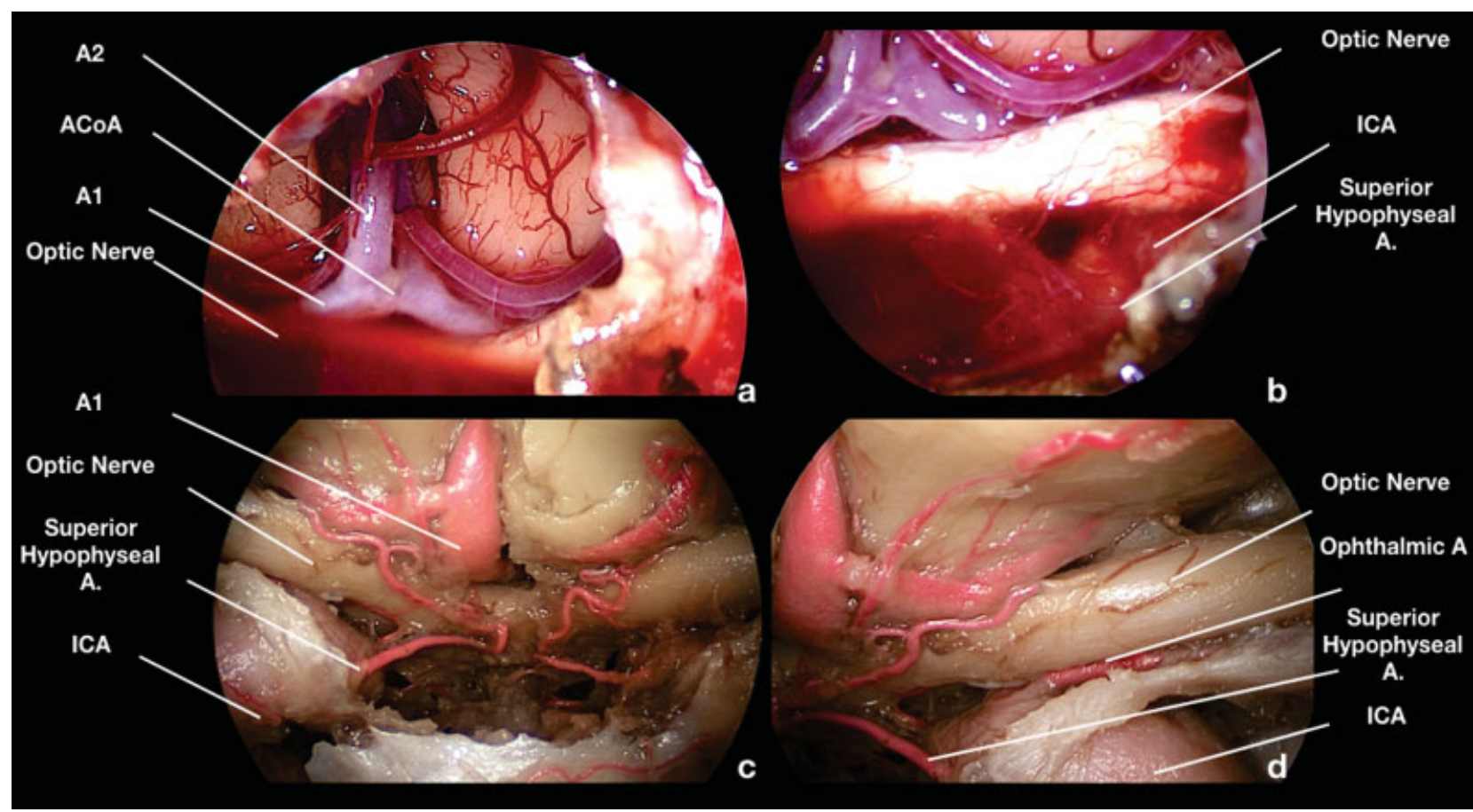

Fig. 9 Intraoperative images and anatomical dissection. $0^{\circ}$ and $30^{\circ}$ scope. Surgical field exploration after resection of a tuberculum sellae meningioma. (a and $\mathbf{b}$ ) At end of the tumor removal the suprasellar region can be explored to detect tumor remnants. The vascular complex of anterior communication artery can be observed. ( $c$ and $\mathbf{d}$ ) The lateral exploration of the surgical field can allow us to visualize a portion of the tumor entering in the optic canal. The superior meningeal artery is also appreciable. Its sparing during surgery permits avoiding vascular injury to optic nerve and to the chiasm. 
affected by the learning curve of the surgical team. In this lapse of time, also the surgical technique and tools have evolved, and this can be a bias for our results. Indeed, our closure strategy has evolved over time, adopting more advanced techniques, such as the gasket seal or the nasoseptal flap, only in the second part of this series. ${ }^{31,32}$ Finally, because of the learning curve, the majority of cases have been operated on in the past 5 years, reducing the follow-up of the entire series.

\section{Conclusion}

Although, the EEA might seem "unnatural" for intradural tumors, such as meningiomas, it could give many advantages for properly selected cases, such as midline noncalcified tumors without lateral extension and vascular encasement. Despite its effectiveness, this approach is hampered by the relevant risk of CSF leak. Therefore, the EEA should be reserved to those selected cases, for which this limit can be counterbalanced by their advantages. Revising our experience in anterior skull base meningioma, we have considered that planum/tuberculum sellae meningiomas are advantageous indications for this approach, allowing us to achieve a good ophthalmologic outcome and a satisfactory tumor removal. Midline frontal sinus and olfactory groove tumors with extracranial extension can also be effectively resected through an EEA. Conversely, for intradural frontal sinus and olfactory groove meningiomas the role of EEA is still to be assessed, comparing its outcome and limitations to modern transcranial approaches.

\section{Note}

The authors state that the content of the submitting manuscript, in part or in full, has not been published previously, and has not been submitted elsewhere for review. There is no financial support received in conjunction with the generation of this submission and no conflict of interest. The Authors certify that this manuscript is a unique submission and is not being considered for publication with any other source in any medium. The Authors have nothing to declare and nothing to disclose.

\section{Acknowledgment}

We thank Dr. Cecilia Baroncini for her linguistic review of the paper.

\section{References}

1 Muskens IS, Briceno V, Ouwehand TL, et al. The endoscopic endonasal approach is not superior to the microscopic transcranial approach for anterior skull base meningiomas-a meta-analysis. Acta Neurochir (Wien) 2018;160(01):59-75

2 Linsler S, Fischer G, Skliarenko V, Stadie A, Oertel J. Endoscopic assisted supraorbital keyhole approach or endoscopic endonasal approach in cases of tuberculum sellae meningioma: which surgical route should be favored? World Neurosurg 2017;104:601-611

3 Kshettry VR, Elshazly K, Evans JJ. Endoscopic transnasal surgery for planum and tuberculum sella meningiomas: decision-making, technique and outcomes. CNS Oncol 2016;5(04):211-222
4 Schroeder HW. Indications and limitations of the endoscopic endonasal approach for anterior cranial base meningiomas. World Neurosurg 2014;82(6, Suppl):S81-S85

5 Clark AJ, Jahangiri A, Garcia RM, et al. Endoscopic surgery for tuberculum sellae meningiomas: a systematic review and metaanalysis. Neurosurg Rev 2013;36(03):349-359

6 Ruggeri AG, Cappelletti M, Fazzolari B, Marotta N, Delfini R. Fronto-basal midline meningiomas: is it right to shed doubt on the transcranial approaches? Updates and review of the literature. World Neurosurg 2016;88:374-382

7 Elshazly K, Kshettry VR, Farrell CJ, Nyquist G, Rosen M, Evans JJ. Clinical outcome after endoscopic endonasal resection of tuberculum sella meningiomas. Oper Neurosurg (Hagerstown) 2018; 14(05):494-502

8 Song SW, Kim YH, Kim JW, et al. Outcomes after transcranial and endoscopic endonasal approach for tuberculum meningiomas-a retrospective comparison. World Neurosurg 2018;109: e434-e445

9 Shetty SR, Ruiz-Treviño AS, Omay SB, Almeida JP, Liang B, Chen YN, et al. Limitations of the endonasal endoscopic approach in treating olfactory groove meningiomas. A systematic review. Acta Neurochir (Wien) 2017;159(10):1875-1885

10 Turel MK, Tsermoulas G, Reddy D, Andrade-Barazarte H, Zadeh G, Gentili F. Endonasal endoscopic transsphenoidal excision of tuberculum sellae meningiomas: a systematic review. J Neurosurg Sci 2016;60(04):463-475

11 Ditzel Filho LF, Prevedello DM, Jamshidi AO, et al. Endoscopic Endonasal Approach for Removal of Tuberculum Sellae Meningiomas. Neurosurg Clin N Am 2015;26(03):349-361

12 Ajlan AM, Choudhri O, Hwang P, Harsh G. Meningiomas of the tuberculum and diaphragma sellae. J Neurol Surg B Skull Base 2015;76(01):74-79

13 Brunworth J, Padhye V, Bassiouni A, et al. Update on endoscopic endonasal resection of skull base meningiomas. Int Forum Allergy Rhinol 2015;5(04):344-352

14 Koutourousiou M, Fernandez-Miranda JC, Stefko ST, Wang EW, Snyderman CH, Gardner PA. Endoscopic endonasal surgery for suprasellar meningiomas: experience with 75 patients. J Neurosurg 2014;120(06):1326-1339

15 Koutourousiou M, Fernandez-Miranda JC, Wang EW, Snyderman $\mathrm{CH}$, Gardner PA. Endoscopic endonasal surgery for olfactory groove meningiomas: outcomes and limitations in 50 patients. Neurosurg Focus 2014;37(04):E8

16 Van Gompel JJ, Frank G, Pasquini E, Zoli M, Hoover J, Lanzino G. Expanded endonasal endoscopic resection of anterior fossa meningiomas: report of 13 cases and meta-analysis of the literature. Neurosurg Focus 2011;30(05):E15

17 Khan OH, Krischek B, Holliman D, et al. Pure endoscopic expanded endonasal approach for olfactory groove and tuberculum sellae meningiomas. J Clin Neurosci 2014;21(06):927-933

18 Mascarella MA, Tewfik MA, Aldosari M, Sirhan D, Zeitouni A, Di Maio S. A simple scoring system to predict the resectability of skull base meningiomas via an endoscopic endonasal approach. World Neurosurg 2016;91:582-591.e1

19 Khan OH, Anand VK, Schwartz TH. Endoscopic endonasal resection of skull base meningiomas: the significance of a "cortical cuff" and brain edema compared with careful case selection and surgical experience in predicting morbidity and extent of resection. Neurosurg Focus 2014;37(04):E7

20 Ottenhausen M, Banu MA, Placantonakis DG, et al. Endoscopic endonasal resection of suprasellar meningiomas: the importance of case selection and experience in determining extent of resection, visual improvement, and complications. World Neurosurg 2014;82(3-4):442-449

21 Jones SH, Iannone AF, Patel KS, et al. The impact of age on long term quality of life after endonasal endoscopic resection of skull base meningiomas. Neurosurgery 2016;79(05):736-745 
22 Abbassy M, Woodard TD, Sindwani R, Recinos PF. An overview of anterior skull base meningiomas and the endoscopic endonasal approach. Otolaryngol Clin North Am 2016;49(01):141-152

23 Padhye V, Naidoo Y, Alexander H, et al. Endoscopic endonasal resection of anterior skull base meningiomas. Otolaryngol Head Neck Surg 2012;147(03):575-582

24 Banu MA, Mehta A, Ottenhausen M, et al. Endoscope-assisted endonasal versus supraorbital keyhole resection of olfactory groove meningiomas: comparison and combination of $2 \mathrm{mini}-$ mally invasive approaches. J Neurosurg 2016;124(03):605-620

25 Liu JK, Silva NA, Sevak IA, Eloy JA. Transbasal versus endoscopic endonasal versus combined approaches for olfactory groove meningiomas: importance of approach selection. Neurosurg Focus 2018;44(04):E8

26 Karsy M, Raheja A, Eli I, Guan J, Couldwell WT. Clinical outcomes with transcranial resection of the tuberculum sellae meningioma. World Neurosurg 2017;108:748-755

27 Mortazavi MM, Brito da Silva H, Ferreira M Jr., Barber JK, Pridgeon JS, Sekhar LN. Planum sphenoidale and tuberculum sellae meningiomas: operative nuances of a modern surgical technique with outcome and proposal of a new classification system. World Neurosurg 2016;86:270-286

28 Zoli M, Manzoli L, Bonfatti R, et al. Endoscopic endonasal anatomy of the ophthalmic artery in the optic canal. Acta Neurochir (Wien) 2016;158(07):1343-1350

29 Attia M, Kandasamy J, Jakimovski D, et al. The importance and timing of optic canal exploration and decompression during endoscopic endonasal resection of tuberculum sella and planum sphenoidale meningiomas. Neurosurgery 2012;71(1, Suppl operative):58-67

30 Abhinav K, Acosta Y, Wang WH, et al. Endoscopic Endonasal Approach to the Optic Canal: Anatomic Considerations and Surgical Relevance. Neurosurgery 2015;11(Suppl 3):431-445, discussion 445-446

31 Garcia-Navarro V, Anand VK, Schwartz TH. Gasket seal closure for extended endonasal endoscopic skull base surgery: efficacy in a large case series. World Neurosurg 2013;80(05):563-568

32 Hadad G, Bassagasteguy L, Carrau RL, et al. A novel reconstructive technique after endoscopic expanded endonasal approaches: vascular pedicle nasoseptal flap. Laryngoscope 2006;116(10):1882-1886 